\title{
7Direct Spectrophotometric Determination of Glimepiride in Pure Form and Pharmaceutical Formulations Using Bromocresol Purple
}

\author{
Abdul Aziz Ramadan ${ }^{1 *}$ and Souad Zeino \\ Department of Chemistry, Faculty of Science, University of Aleppo, Syria. \\ *1E-mail : dramadan@scs-net.org, Fax : (963) (21)2633136.
}

\begin{abstract}
A simple, direct and accurate spectrophotometric method has been developed for the determination of Glimepiride (GLM) in pure and pharmaceutical formulations by complex formation with bromocresol purple $(B C P)$. The method involves the formation of a yellow ion-pair complex between BCP with glimepiride at $\mathrm{pH}<3,8$; after reacting GLM with $\mathrm{Na}_{2} \mathrm{CO}_{3}$ to give $\mathrm{C}_{24} \mathrm{H}_{33} \mathrm{~N}_{4} \mathrm{H}^{+} \mathrm{O}_{5} \mathrm{NaS}$ which is extracted by chloroform. The formed complex [GLM]: [ BCP] was measured at $\lambda_{\max } 418 \mathrm{~nm}$ against the reagent blank prepared in the same manner. Variables were studied in order to optimize the reaction conditions. Molar absorptivity $(\varepsilon)$ for complex was $20600 \mathrm{~L} . \mathrm{mol}^{-1} . \mathrm{cm}^{-1}$. Beer's law was obeyed in the concentration range of $1.226-46.608 \mu \mathrm{g} . \mathrm{mL}^{-1}$ in present of $5.0 \times 10^{-4} \mathrm{~mol} / \mathrm{l}$ of $\mathrm{BCP}$ with good correlation coefficient $\left(\mathrm{R}^{2}=0.9997\right)$. The relative standard deviation did not exceed 3.6\%. The limit of detection (LOD) and the limit of quantification (LOQ) were 0.15 and $0.46 \mu \mathrm{g}$. $\mathrm{mL}^{-1}$, respectively. The proposed method was validated for specificity, linearity, precision and accuracy, repeatability, sensitivity (LOD and LOQ) and robustness. The developed method is applicable for the determination of GLM in pure and different dosage forms with average assay of 98.8 to $102.0 \%$ and the results are in good agreement with those obtained by the RP-HPLC reference method.
\end{abstract}

Keywords. Direct spectrophotometric method; Ion-pair complex; Glimepiride; Bromocresol purple.

Date of Submission: 2018-05-31

Date of Acceptance: 2018-06-20

Date of Publication: 2018-07-04

DOI 10.24297/jac.v15i2.7454

ISSN: 2321-807X

Volume: 15 Issue: 02

Journal: Journal of Advances in Chemistry

Website: https://cirworld.com

This work is licensed under a Creative Commons Attribution 4.0 International License. 


\section{INTRODUCTION}

Glimepiride (GLM) belongs to sulfonylurea oral anti diabetic and GLM is an anti-diabetic drug which is used for the treatment of diabetes. GLM is a white to yellowish-white, odorless, crystalline powder insoluble in water. It is chemically described as 1-[[p-[2-(3-ethyl-4methyl-2-oxo-3-pyrroline-1carboxamido) ethyl] phenyl] sulfonyl]-3-(trans-4-methylcyclohexyl) urea $\left(\mathrm{C}_{24} \mathrm{H}_{34} \mathrm{~N}_{4} \mathrm{O}{ }_{5} \mathrm{~S}\right)$ with a mol. mass of $490.62 \mathrm{~g}[1,3]$, see Scheme 1 .

Bromocresol purple $\mathrm{C}_{21} \mathrm{H}_{16} \mathrm{Br}_{2} \mathrm{O}_{5} \mathrm{~S}(\mathrm{BCP})$, acts as a weak acid in solution. It can thus be in protonated or deprotonated form, appearing yellow or purple, respectively, mol. mass $540.22 \mathrm{~g}$ [4], see scheme 2 . Bromocresol purple has been used as a reagent to form ion pair complexes with drugs as gatifloxacin [5].

Scheme 1: Chemical structure of Glimepiride (GLM).

Scheme 2: Chemical structure of Bromo cresol purple (BCP).

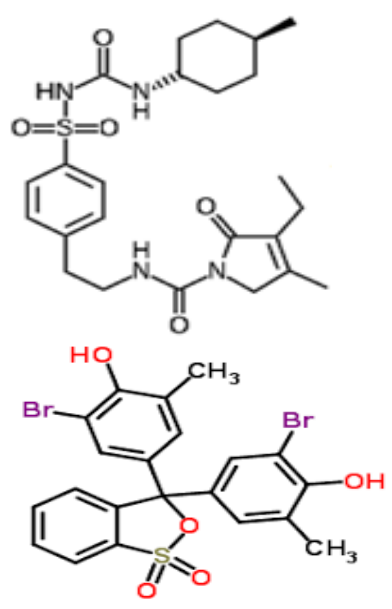

The objective of present study was to develop and validate an analytical method for quantitative determination and dissolution studies of glimepiride in tablets. The glimepiride shows absorption maxima at $225 \mathrm{~nm}$ and obeyed Beer's law in the range of $6.0-14.0 \mu \mathrm{g} \cdot \mathrm{mL}^{-1}$. The limit of detection and limit of quantitation were 0.06 , and $0.17 \mu \mathrm{g} \cdot \mathrm{mL}^{-1}$ respectively. Percentage recovery of glimepiride for the proposed method ranged from 99.32 to $100.98 \%$ indicating no interference of the tablet excipients. It was concluded that the proposed method is simple, easy to apply, economical and used as an alternative to the existing spectrophotometric and non-spectrophotometric methods for the routine analysis of glimepiride in pharmaceutical formulations and in vitro dissolution studies. [6].

Two simple and sensitive visible spectrophotometric methods have been developed for the quantitative estimation of glimepiride from its tablet formulation. The developed methods are based on formation of chloroform extractable coloured complex of drug with methylene blue and safranine. The chloroform extracted complex of drug with methylene blue showed absorbance maxima at $652 \mathrm{~nm}$ and linearity was observed in the concentration range of $15-50 \mu \mathrm{g} \cdot \mathrm{mL}^{-1}$ (method-I), with safranine showed absorbance maxima at $536 \mathrm{~nm}$ and linearity was observed in the concentration range of $10-80 \mu \mathrm{g} / \mathrm{mL}$ (method-II). Results of analysis for both the developed methodswere validated statistically and by recovery studies. [7].

Various spectrophotometric methods [8-28] have been reported for the determination of Glimepiride in pure as well as in dosage forms. Most spectrophotometric methods employ extraction procedures. In this case, the extracted complexes were into an organic solvent, which is immiscible with water, and the concentration of the resulting complex in the organic phase is determined spectrophotometrically. The complex extraction technique has some difficulties and inaccuracies due to incomplete extraction or the formation of emulsions between the hydrocarbon solvent and the basic compound-containing solution. In response to the problems resulting from extraction of the complex, it is better to determine formed complex without extraction [29]. Also, none of the methods reported in the literatures is based on the formation of complex between BCP and GLM. 
In this study, extraction-free spectrophotometric method for determination of GLM through ion-pair complex formation with BCP was developed.

\section{MATERIALS AND METHODS}

\subsection{Equipment and Materials}

Spectrophotometric measurements were made in Spectro scan 80 DV UV-VIS spectrophotometr with $1 \mathrm{~cm}$ quartz cells. An ultrasonic processor model Powersonic 405 was used to sonicate the sample solutions. The diluter pipette model DIP-1 (Shimadzu), having $100 \mu \mathrm{l}$ sample syringe and five continuously adjustable pipettes covering a volume range from 20 to $5000 \mu \mathrm{L}$ (model Piptman P, GILSON). Centrifuge (Centurion Scientific Ltd., Model: K2080-Manufactured in the United Kingdom) was used for preparation of the experimental solutions. SARTORIUS TE64 electronic balance was used for weighing the samples.

We used glimepiride (99.98\%) was supplied by Chempi fine chemicals (INDIA), Metformin HCL (99.0\%) and Rosuvastatin Calcium (98.6\%). Bromocresol purple (99\%) of analytical grade, chloroform Sigma-Aldrich and $\mathrm{Na}_{2} \mathrm{CO}_{3}$ extra pure were from MERCK. All solvents and reagents were analytical grade chemicals.

Tablet commercial formulations were used for the analysis of GLM. The pharmaceutical formulations subjected to the analytical procedure were:

(1) Amarium tablets, Racha Lab, Aleppo-Syria, each tablet contains 2 and $4 \mathrm{mg}$ of GLM (Mfg. 5/2016, Exp. 5/2018, respectively).

(2) Amapiride tablets, Avenzor Pharmaceutical Industries, Damascus-Syria, each tablet contains 2 and $4 \mathrm{mg}$ of GLM (Mfg. 7/2017, Exp. 7/2019, respectively).

\subsection{Standard stock solutions}

$1 \times 10^{-3} \mathrm{~mol}$. L-1 of pure GLM was prepared in chloroform. This solution was prepared by good mixing $12.27 \mathrm{mg}$ of GLM with $0.05 \mathrm{~g}$ of $\mathrm{Na}_{2} \mathrm{CO}_{3}$, adding $0.1 \mathrm{~mL} \mathrm{H} \mathrm{H}_{2} \mathrm{O}$, drying well in $105^{\circ} \mathrm{C}$, after that it was dissolved in chloroform into a volumetric flask $(25 \mathrm{~mL})$ and diluted up to mark with chloroform. The solution was stored in dark bottles and kept in the refrigerator for not more than a week. The stock solution was further diluted daily just before the use to obtain working solutions of GLM in the concentration range 2.5-95 $\mu \mathrm{M}(1.226-46.608$ $\mu \mathrm{g} \cdot \mathrm{mL}^{-1}$ of $\left.\mathrm{GLM}\right)$.

Stock standard solution of Bromocresol purple (BCP) $1 \times 10^{-2}$ mol/l: Accurately weighed $136.42 \mathrm{mg}$ of BCP was dissolved in chloroform into a volumetric flask $(25 \mathrm{~mL})$ and diluted up to mark with chloroform.

\subsection{Recommended Procedure}

Aliquots of $1 \times 10^{-3} \mathrm{~mol}$. L-1 GLM solution $(25,50,75,100,200,300,400,500,600,750,850$ and $950 \mu \mathrm{L})$ containing $2.5,5,7.5,10,20,30,40,50,60,75,85$ and $95 \mu \mathrm{M}(1.226,2.453,3.680,4.906,9.812,14.719$, $19.625,24.531,29.437,36.797,41.703$, and $46.608 \mu \mathrm{g} . \mathrm{mL}^{-1}$ ) of GLM were transferred into a series of $10 \mathrm{~mL}$ calibrated volumetric flasks. Then $0.500 \mathrm{~mL}$ of BCP solution $\left(1 \times 10^{-2} \mathrm{~mol}\right.$. L-1) was added. The volume was made up to the mark with solvent and the absorbance was measured at $\lambda_{\max } 418 \mathrm{~nm}$ in chloroform, against a similar reagent blank.

\subsection{Procedure for pharmaceutical formulations}

Twenty tablets of each studied pharmaceutical formulation were weighed accurately, finely powdered and mixed well. An amount of the powder equivalent to the weight of one tablet was mixed well with $0.05 \mathrm{~g}$ of $\mathrm{Na}_{2} \mathrm{CO}_{3}$, adding $0.1 \mathrm{ml} \mathrm{H} \mathrm{O}_{2}$, drying well in $105^{\circ} \mathrm{C}$, and solved in chloroform using ultrasonic for $15 \mathrm{~min}, 10 \mathrm{ml}$ 
of chloroform was added, filtered over a $10 \mathrm{ml}$ flask and washed by the same solvent, then diluted to $10 \mathrm{ml}$ with chloroform. This solution contains the following: 200 and $400 \mu \mathrm{g} \cdot \mathrm{mL}^{-1}$ of GLM for all studied pharmaceutical formulations contain 2 and $4 \mathrm{mg} / \mathrm{tab}$, respectively.

Five solutions were prepared daily by diluting $1.0 \mathrm{~mL}$ from each stock solution of pharmaceutical formulations for contents: 2 or $4 \mathrm{mg} / \mathrm{tab}$, then $0.4 \mathrm{ml}$ from stock standard solution of BCP was added and adjusted the volume up to $10 \mathrm{ml}$ with chloroform (these solutions contain 20 or $40 \mu \mathrm{g}$. $\mathrm{mL}^{-1}$ of GLM respectively and $4 \times 10^{-4}$ mol. $\mathrm{L}^{-1}$ of $\mathrm{BCP}$; test solutions).

\section{RESULTS AND DISCUSSION}

\subsection{The effect of solvent}

The effect of the solvents (acetone, acetonitrile, dichloroethane, dichloromethane, chloroform and ethylacetate) on absorbance of reagent (BCP), formed complex [GLM][BCP] and the difference between them. It was found that chloroform solvent was the best, see Figure 1.

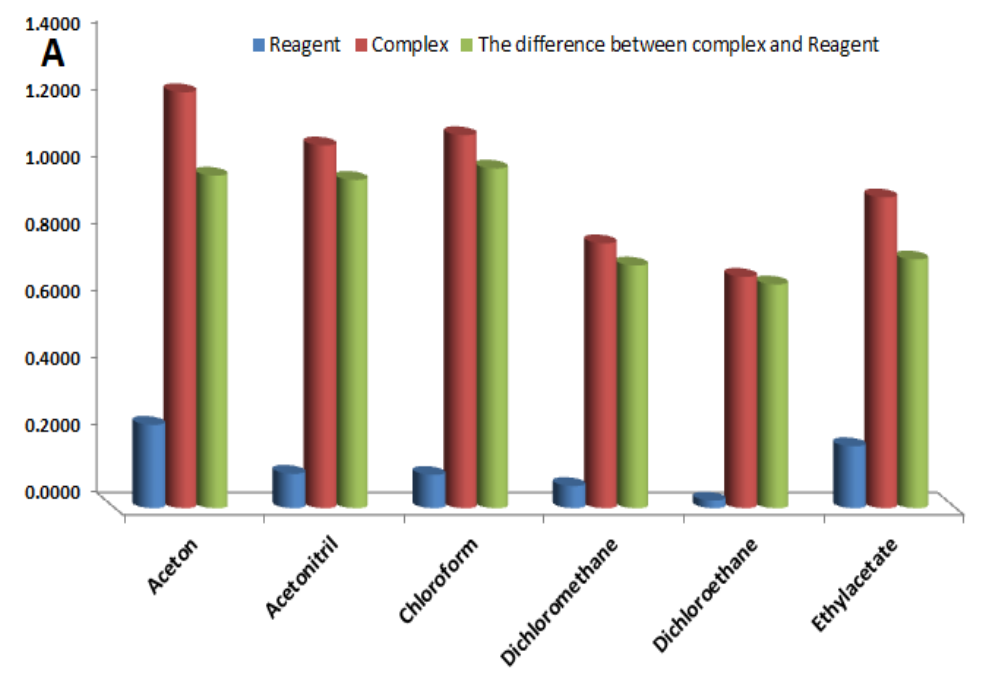

Fig. 1: Absorbance of reagent $(B C P)$, formed complex [GLM]: [ $B C P]$ and

difference between them $\left(C_{B C P} 2.5 \times 10^{-4} \mathrm{M}, C_{\text {Complex }} 5 \times 10^{-5} \mathrm{M}\right.$, Blank is solvent, $\left.\ell=1 \mathrm{~cm}\right)$.

\subsection{Absorption Spectra}

UV-Vis spectra of GLM, BCP and the formed complex GLM:BCP solutions in chloroform was obtained. GLM solutions do not absorb in the range $300-600 \mathrm{~nm}$. BCP solutions have small absorption at $\lambda_{\max } 418 \mathrm{~nm}$ $\left(\varepsilon \approx 396 \mathrm{~L} \mathrm{~mol}^{-1} \mathrm{~cm}^{-1}\right.$ in chloroform). [GLM]: [BCP] complex solutions have maximum absorption at $\lambda_{\max } 418 \mathrm{~nm}$ in chloroform, $\varepsilon$ for the complex was $20600 \mathrm{~L} \mathrm{~mol}^{-1} \mathrm{~cm}^{-1}$, see Figure 2 as example.

\subsection{Optimization of Variables}

The different experimental parameters affecting the spectrophotometric determination of GLM through ionpair complex [GLM]: [BCP] formation with $B C P$ in chloroform was studied in order to determine the optimal conditions for the determination of GLM. 


\subsection{The effect of time and temperature}

The effect of time and temperature on the complex [GLM]: [BCP] formation was studied within the ranges 5$120 \mathrm{~min}$ and $15-45^{\circ} \mathrm{C}$. It was found that the formed complex wasn't affected by time or temperature at those ranges.

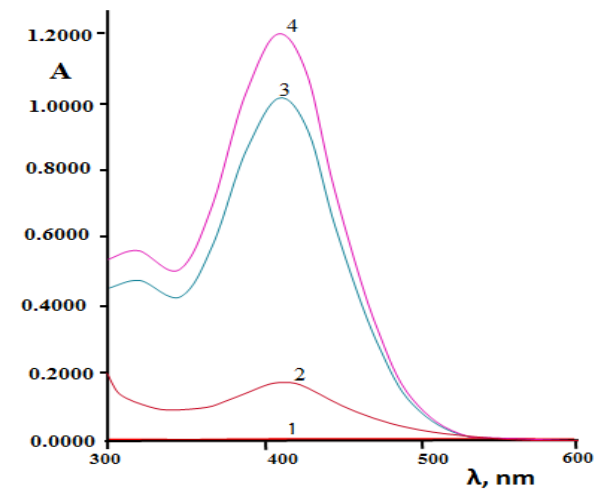

Fig.2. UV-Vis spectra in chloroform of: $1-0.8 \times 10^{-4} \mathrm{~mol}^{-L^{-1}}$ of GLM; $2-5.0 \times 10^{-4} \mathrm{~mol}^{-L^{-1}}$ of $B C P ; 3-0.5 \times 10^{-4}$ mol.L- ${ }^{-1}$ ion-pair complex $\left(0.5 \times 10^{-4} \mathrm{~mol}^{-L^{-1}}\right.$ of GLM with $5 \times 10^{-4} \mathrm{~mol} . \mathrm{L}^{-1}$ of $\left.\mathrm{BCP}\right)$; Blank is $5.0 \times 10^{-4} \mathrm{~mol} / \mathrm{l}$ of $B C P, 4-0.5 \times 10^{-4}$ mol. $L^{-1}$ ion-pair complex $\left(0.5 \times 10^{-4} \mathrm{~mol}^{-L^{-1}}\right.$ of GLM with $5 \times 10^{-4} \mathrm{~mol}^{-L^{-1}}$ of $\left.B C P\right)$; Blank is chloroform, $\ell=1 \mathrm{~cm}$.

\subsection{The effect of BCP concentration}

The effect of $B C P$ concentration on complex [GLM]: $[B C P]$ formation was investigated. It was observed that the absorbance of the formed complex increased coinciding with increasing the ratio of $C_{B C P}: C_{G L M}$ until the ratio (5:1), then slowly increased until the absorbance became a quasi-static at ratio more than 10 .

\subsection{Stoichiometric Relationship}

\subsubsection{The molar ratio method}

The composition of GLM:BCP complex were determined by the molar ratio method and Job's method of continuous variation [30]. The stoichiometry of GLM: BCP complex was studied by molar ratio method according to following equation: $A_{\max }=f([B C P] /[G L M])$ at $\lambda_{\max } 418 \mathrm{~nm}$ in chloroform. It confirmed that the binding ratio of GLM: BCP complexes are equal to (1:1); where the concentration of GLM was constant (50 $\mu \mathrm{M})$ and the concentrations of $\mathrm{BCP}$ changed from 0 to $250 \mu \mathrm{M}$, see Figure 3. The formation constant of the ion pair complex [GLM]: [ BCP] is $2.81 \times 10^{8}$ in chloroform.

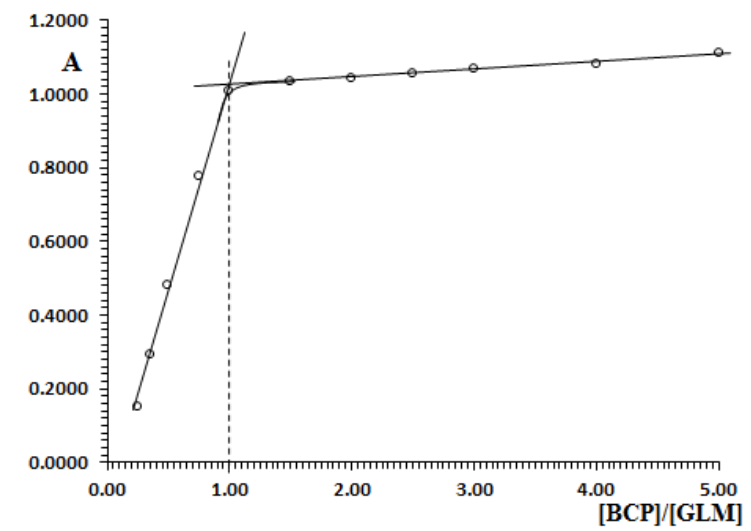

Fig.3. Molar ratio method to calculate binding ratio of GLM:BCP complex at $\lambda_{\max } 418 \mathrm{~nm}$ in chloroform

$$
\text { ([GLM] }=50 \mu \mathrm{M} \text {, blank is chloroform, } \ell=1 \mathrm{~cm} \text { ). }
$$




\subsubsection{The Job's method}

Continuous variation was utilized to check the composition of GLM:BCP complex at $\lambda_{\max } 418 \mathrm{~nm}$ in chloroform. The absorbance of the complex in used solvent were plotted against the mole fraction $[B C P] /([G L M]+[B C P])$, where $[G L M]+[B C P]=100 \mu \mathrm{M}$. The plot reached maximum value at a mole fraction of 0.5 , see Figure 4 . This indicated complex formation (GLM: BCP) in the ratio of (1:1). The formation constant of the ion- pair complex [GLM]: [BCP] is $2.44 \times 10^{8}$.

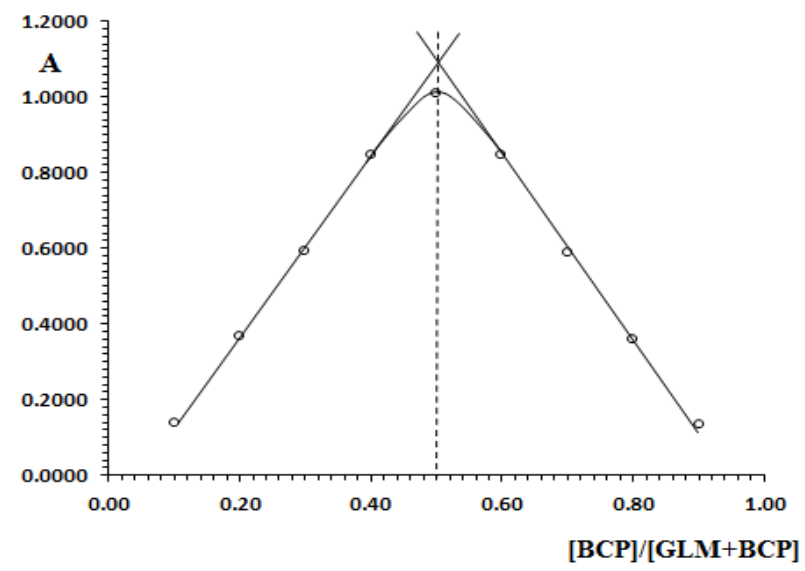

Fig.4. Job's method of continuous variation to calculate binding ratio of GLM: BCP complex at $\lambda_{\max } 418 \mathrm{~nm}$ in chloroform $([\mathrm{GLM}]+[\mathrm{BCP}]=100 \mu \mathrm{M}$, blank is chloroform, $\ell=1 \mathrm{~cm})$.

\subsection{Mechanism of reaction}

Anionic dyes such as BCP form ion-pair complexes with the positively charged nitrogen-containing molecule. The colour of such dyes is due to the opening of lactoid ring and subsequent formation of quinoid group (deprotonated). Glimepiride $\left(\mathrm{C}_{24} \mathrm{H}_{34} \mathrm{~N}_{4} \mathrm{O}_{5} \mathrm{~S}\right)$ is reacted with $\mathrm{Na}_{2} \mathrm{CO}_{3}$ to give $\left(\mathrm{C}_{24} \mathrm{H}_{33} \mathrm{~N}_{4} \mathrm{H}^{+} \mathrm{O}_{5} \mathrm{NaS}\right)$, then dissolved in chloroform and forms yellow ion-pair complex with the dye at $\mathrm{pH}<3.8$; (in $\mathrm{pH}>5.4$ and alkaline solution $\mathrm{BCP}$ gives blue colour). Each drug-dye complex with two oppositely charged ions (positive on the drug and negative on the dye) behaves as a single unit held together by an electrostatic binding [14, 24-27]. The suggested mechanism of GLM- BCP ion-pair complex formation is shown in Scheme 3.
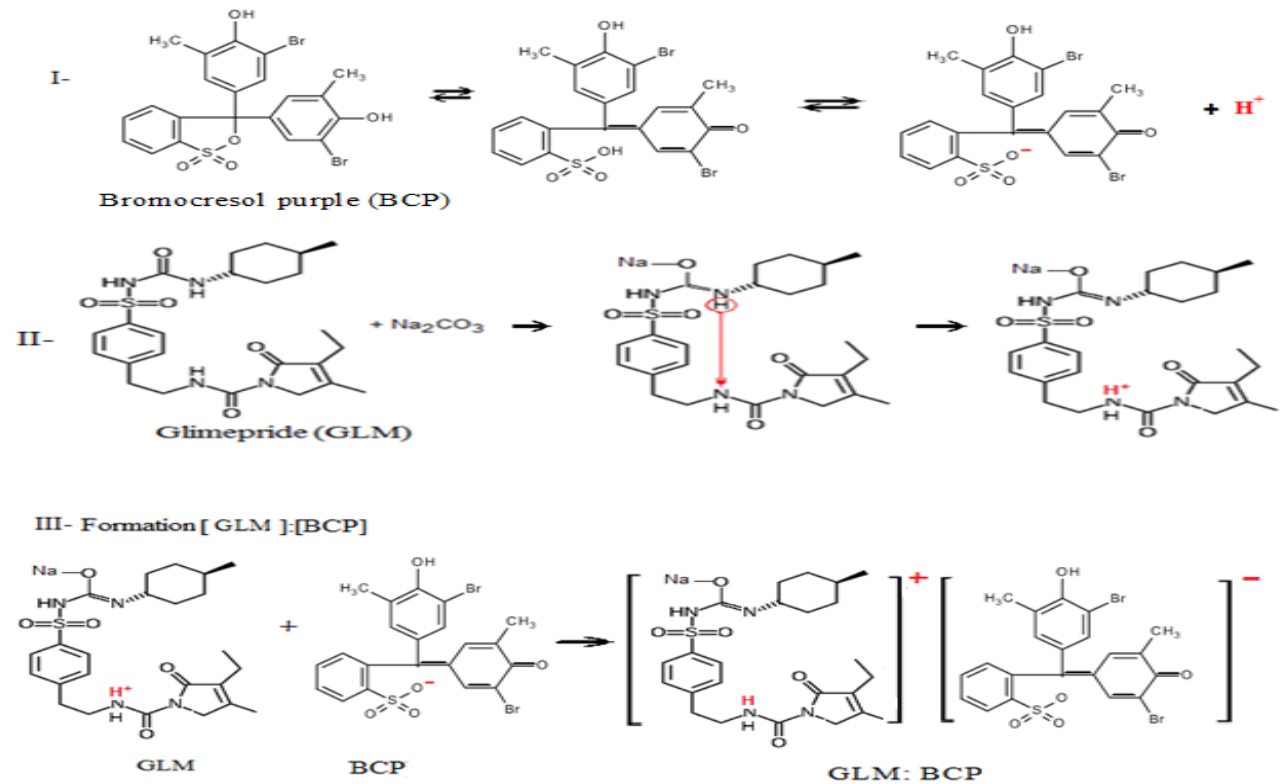

Scheme 3: The possible reaction mechanism of [GLM]: [BCP] complex formation. 


\subsection{Calibration curve}

The calibration curve of GLM in pure form through complexation with BCP showed excellent linearity over concentration range of $1.226-46.608 \mu \mathrm{g} . \mathrm{mL}^{-1}$ in presence of $5.0 \times 10^{-4} \mathrm{~mol}^{-1} \mathrm{~L}^{-1}$ of BCP with good correlation coefficient $\left(R^{2}=0.9997\right)$ in chloroform. Regression equation at $\lambda_{\max }$ was as the follows: $y=0.0421 x+0.0023$ in chloroform. Figures 5 and 6 showed the spectra of [GLM]: [ BCP] complex in presence of $5.0 \times 10^{-4} \mathrm{M}$ of BCP as example. The spectra characteristics of the method such as the molar absorptivity $(\varepsilon)$, Beer's law, regression equation at $\lambda_{\max }(y=a . x+b)$; where $y=$ absorbance, $a=$ slope, $x=$ concentration of $G L M$ by $\mu g . \mathrm{mL}^{-1}, b=$ intercept, the correlation coefficient, limit of detection (LOD) and limit of quantification (LOQ) and the optimum conditions for spectrophotometric determination of GLM through ion-pair complex formation using BCP in chloroform is summarized in Table 1.

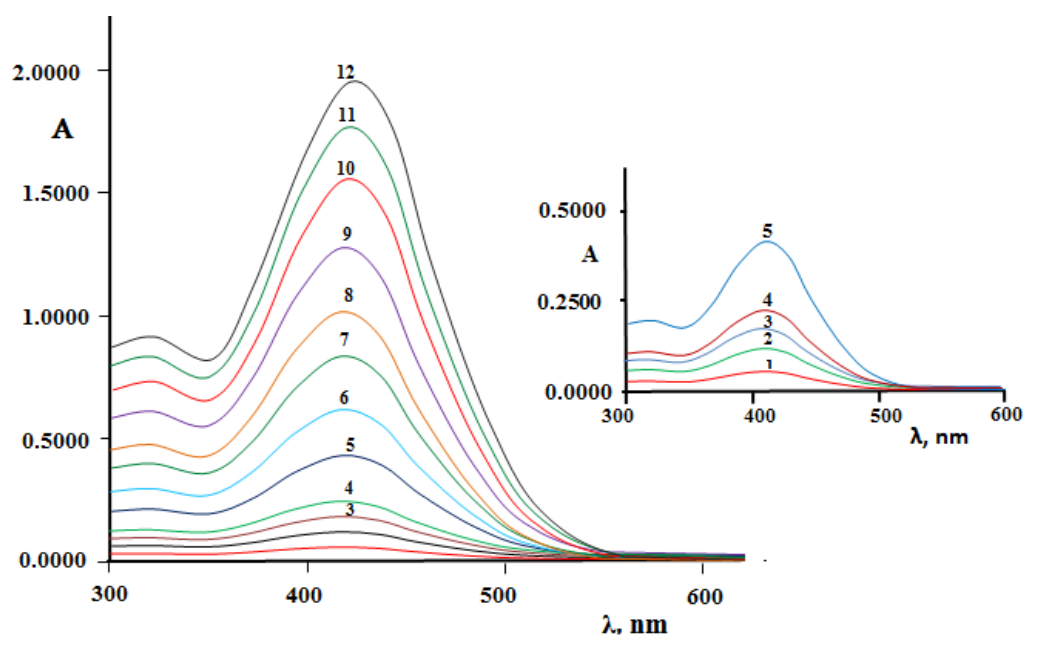

Fig.5. Spectra of [GLM]: [BCP] complex in presence of $5.0 \times 10^{-4} \mathrm{M}$ of $B C P$; where $\mathrm{C}_{\mathrm{GLM}}$ as the follows: 1.226 , $2.453,3.680,4.906,9.812,14.719,19.625,24.531,29.437,36.797,41.703$ and $46.608 \mu \mathrm{g} . \mathrm{mL}^{-1}$ (Blank is BCP solution in chloroform $\left.5.0 \times 10^{-4} \mathrm{M} ; \ell=1 \mathrm{~cm}\right\}$.

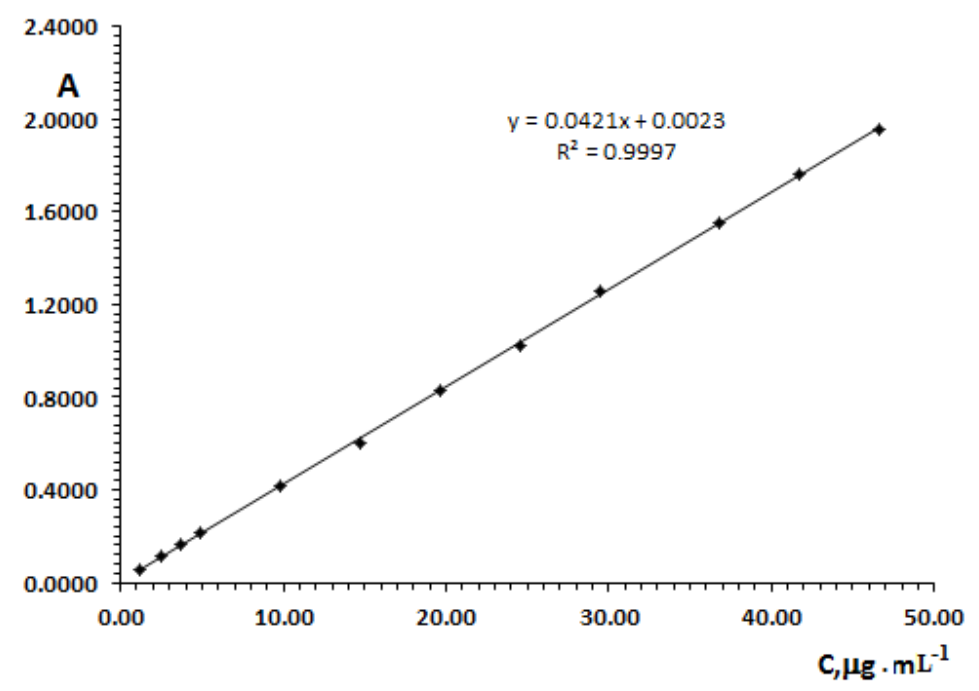

Fig. 6: Calibration curve for determination of GLM according to optimal conditions at $\lambda \max 418 \mathrm{~nm}$ (in present of $5.0 \times 10^{-4} \mathrm{M}$ of $\mathrm{BCP}$ ) where GLM: $1.226-46.608 \mu \mathrm{g} \cdot \mathrm{mL}^{-1}$ \{Blank is BCP solution in chloroform $5.0 \times 10^{-4} \mathrm{M} ; \ell=1$ $\mathrm{cm}\}$. 
Table 1. The parameters established for spectrophotometric determination of GLM by complex formation with $\mathrm{BCP}$ in chloroform.

\begin{tabular}{|c|c|}
\hline Parameters & Operating values \\
\hline$\lambda_{\max }$ of GLM: CPB complex, $\mathrm{nm}$ & 418 \\
\hline Beer's Law Limit, for $C_{G L M}$ by $\mu M$ & $2.5-95$ \\
\hline Beer's Law Limit, for $C_{G L M}$ by $\mu \mathrm{g} \cdot \mathrm{mL}^{-1}$ & $1.226-46.608$ \\
\hline Molar absorptivity of [GLM]: [BCP] complex $(\varepsilon), \mathrm{L} \cdot \mathrm{mol}^{-1} \cdot \mathrm{cm}^{-1}$ & 20600 \\
\hline \multicolumn{2}{|l|}{ Regression equation for [GLM]: $[\mathrm{BCP}]$ at $\lambda_{\max }=418 \mathrm{~nm}$ : } \\
\hline Slope & 0.0421 \\
\hline Intercept & 0.0023 \\
\hline Correlation coefficient $\left(R^{2}\right)$ & 0.9997 \\
\hline LOD for $C_{G L M}$ by $\mu \mathrm{g} \cdot \mathrm{mL}^{-1}$ & 0.15 \\
\hline $\mathrm{LOQ}$ for $\mathrm{C}_{\mathrm{GLM}}$ by $\mu \mathrm{g} \cdot \mathrm{mL}^{-1}$ & 0.46 \\
\hline RSD\% & 3.6 \\
\hline $\mathrm{C}_{\mathrm{BCP}}: \mathrm{C}_{\mathrm{GLM}}, \mathrm{M}$ & $\geq 5$ \\
\hline Stability & $24 \mathrm{~h}$ \\
\hline Temperature of solution & $20 \pm 5^{\circ} \mathrm{C}$ \\
\hline
\end{tabular}
$\mathrm{n}=5, \mathrm{t}=2.776$.

\section{Analytical results}

Spectrophotometric determination of GLM through complexation with BCP in chloroform within optimal conditions using calibration curve was applied. The results, summarized in Table 2, showed that the determined concentration of GLM was rectilinear over the range of $1.226-46.608 \mu \mathrm{g} . \mathrm{mL}^{-1}$, with relative standard deviation (RSD) not more than $3.6 \%$. The results obtained from the developed method have been compared with the official RP-HPLC method [30] and good agreement was observed between them.

Table 2: Spectrophotometric determination of GLM through complex formation with BCP within optimal conditions using calibration curve in chloroform.

\begin{tabular}{|c|c|c|c|c|}
\hline $\begin{array}{c}\mathbf{X}_{\mathbf{i}_{\prime}} \\
\mu \mathrm{g} \cdot \mathrm{mL}^{-1} \text { (Taken) }\end{array}$ & $\begin{array}{l}{ }^{*} \bar{X} \pm S D \\
\mu g . ~ m L^{-1} \\
\text { (Found) }\end{array}$ & $\begin{array}{l}-\bar{x} \pm \frac{t \cdot S D}{\sqrt{n}} \\
\mu \mathbf{g} \cdot \mathbf{m L}^{-1}\end{array}$ & RSD\% & $\begin{array}{c}* X, \mu g . \mathbf{m L}^{-1} \\
\text { RP-HPLC [31] }\end{array}$ \\
\hline 1.226 & $1.235 \pm 0.0445$ & $1.235 \pm 0.0552$ & 3.6 & 1.216 \\
\hline 2.453 & $2.553 \pm 0.087$ & $2.553 \pm 0.108$ & 3.4 & 2.436 \\
\hline 3.680 & $3.824 \pm 0.122$ & $3.824 \pm 0.152$ & 3.2 & 3.721 \\
\hline 4.906 & $5.064 \pm 0.152$ & $5.064 \pm 0.189$ & 3.0 & 4.926 \\
\hline 9.812 & $9.812 \pm 0.294$ & $9.812 \pm 0.365$ & 3.0 & 9.925 \\
\hline 14.719 & $14.316 \pm 0.429$ & $14.316 \pm 0.533$ & 3.0 & 14.897 \\
\hline 19.625 & $19.637 \pm 0.550$ & $19.637 \pm 0.683$ & 2.8 & 18.782 \\
\hline 24.531 & $24.133 \pm 0.627$ & $24.133 \pm 0.779$ & 2.6 & 25.214 \\
\hline 29.437 & $29.732 \pm 0.743$ & $29.732 \pm 0.923$ & 2.5 & 29.890 \\
\hline 36.797 & $36.805 \pm 0.883$ & $36.805 \pm 1.097$ & 2.4 & 38.125 \\
\hline 41.703 & $41.722 \pm 0.960$ & $41.722 \pm 1.191$ & 2.3 & 42.250 \\
\hline 46.608 & $46.456 \pm 1.022$ & $46.456 \pm 1.2688$ & 2.2 & 46.889 \\
\hline
\end{tabular}

${ }^{*} \mathrm{n}=5, \mathrm{t}=2.776$. 


\section{Applications}

The developed spectrophotometric method was applied to determine GLM in some pharmaceutical preparations through complex formation by BCP in chloroform according to the optimal conditions. The results of quantitative analysis for GLM in pharmaceutical preparations were summarized in Table 3 . The proposed method was simple, direct, specific and successfully applied to the determination of GLM in pharmaceuticals without any interference from excipients. Average recovery ranged between 98.8 to $102.0 \%$. The results obtained by this method agree well with the contents stated on the labels and were validated by RP-HPLC method [31].

Table 3: Determination of GLM, in some Syrian pharmaceutical preparations using spectrophotometric method through complex formation with BCP in chloroform, $\lambda_{\max } 418 \mathrm{~nm}$.

\begin{tabular}{|c|c|c|c|c|c|c|}
\hline $\begin{array}{l}\text { Tablet dosage } \\
\text { form }\end{array}$ & $\begin{array}{l}\text { Label Claim } \\
\text { of GLM, } \\
\text { mg/tab. }\end{array}$ & $\begin{array}{c}{ }^{*} \text { Mean } \pm \text { SD } \\
\text { (GLM), } \\
\text { mg/tab. }\end{array}$ & RSD\% & Assay \% & $\begin{array}{c}{ }^{*} \text { Mean } \pm \text { SD } \\
\text { (GLM), } \\
\text { mg/tab. } \\
\text { by RP-HPLC } \\
\text { [31] }\end{array}$ & $\begin{array}{c}\text { * Assay \%, } \\
\text { by RP-HPLC } \\
\text { [31] }\end{array}$ \\
\hline \multirow{2}{*}{ Amarium } & 2 & $1.990 \pm 0.062$ & 3.1 & 99.5 & $2.016 \pm 0.042$ & 100.8 \\
\hline & 4 & $3.972 \pm 0.111$ & 2.8 & 99.3 & $3.996 \pm 0.056$ & 99.9 \\
\hline \multirow{2}{*}{ Amapiride } & 2 & $2.040 \pm 0.061$ & 3.0 & 102.0 & $2.030 \pm 0.038$ & 101.5 \\
\hline & 4 & $3.952 \pm 0.115$ & 2.9 & 98.8 & $3.960 \pm 0.055$ & 99.0 \\
\hline
\end{tabular}

${ }^{*} \mathrm{n}=5$.

\section{METHOD VALIDATION}

The developed method for simultaneous estimation of GLM has been validated in accordance with the International Conference on Harmonization guidelines (ICH) [32].

\subsection{Selectivity and Specificity}

Selectivity test determines the effect of excipients on the assay result. To determine the selectivity of the method, standard solution of GLM, commercial product solution and blank solutions were analyzed. The results of the tests proved that the components other than the drug did not produce any interfere. The specificity of the method was ascertained by analyzing standard GLM in presence of excipients. There was no interference from most of the common excipients.

\subsection{Linearity}

Several aliquots of standard stock solution of GLM were taken in different $10 \mathrm{ml}$ volumetric flask and diluted up to the mark with chloroform such that their final concentrations were $1.226-46.608 \mu \mathrm{g}$. $\mathrm{mL}^{-1}$ for GLM. Absorbance was plotted against the corresponding concentrations to obtain the calibration graph, see Figure 5 and Table 3. Linearity equations obtained were $y=0.042 x+0.0023$ for the range $1.226-46.608 \mu \mathrm{g} . \mathrm{mL}^{-1}$ $\left(R^{2}=0.9997\right)$.

\subsection{Precision and Accuracy}

The precision and accuracy of proposed method was checked by recovery study by addition of standard drug solution to pre-analyzed sample solution at three different concentration levels ( $80 \%, 100 \%$ and $120 \%)$ within the range of linearity for GLM. The basic concentration level of sample solution selected for spiking of the GLM standard solution was $14.719 \mu \mathrm{g} . \mathrm{mL}^{-1}$. The proposed method was validated statistically and through 
recovery studies and was successfully applied for the determination of GLM in pure and dosage forms with percent recoveries ranged from $99.8 \%$ to $102.2 \%$, see Table 4 .

Table 4: Results of recovery studies $(n=5)$.

\begin{tabular}{|c|c|}
\hline Level & \% Recovery \\
\hline $80 \%$ & 100.1 \\
\hline $100 \%$ & 99.8 \\
\hline $120 \%$ & 102.2 \\
\hline
\end{tabular}

\subsection{Repeatability and Robustness}

The repeatability was evaluated by performing 10 repeat measurements for $14.719 \mu \mathrm{g} \cdot \mathrm{mL}^{-1}$ of GLM using the studied spectrophotometric method under the optimum conditions. The found amount of GLM ( $\overline{\mathbf{X}} \pm$ SD) $14.338 \pm 0.420 \mu \mathrm{g} . \mathrm{mL}^{-1}$ and the percentage recovery was found to be $99.7 \pm 2.85$. These values indicate that the proposed method has high repeatability for GLM analysis. The robustness of the method adopted is demonstrated by the constancy of the absorbance with the deliberated minor change in the experimental parameters such as the change in the concentration of excipients, $\mathrm{C}_{\mathrm{BCP}}$ : CGLM $(10 \pm 5 \%)$, temperature $\left(20 \pm 5^{\circ} \mathrm{C}\right)$, stability $(24 \pm 0.5 \mathrm{~h})$ and reaction time $(5 \pm 1 \mathrm{~min})$, see Table 5 which indicates the robustness of the proposed method. The absorbance was measured and assay was calculated for five times.

Table 5: Robustness of the proposed spectrophotometric method.

\begin{tabular}{|c|c|c|}
\hline \multirow{3}{*}{$\begin{array}{c}\text { Experimental parameter } \\
\text { variation }\end{array}$} & \multicolumn{2}{|c|}{ Average recovery (\%)* } \\
\hline & \multicolumn{2}{|c|}{$\mathrm{C}_{\mathrm{GLM}}$} \\
\hline & $4.906 \mu \mathrm{g} \cdot \mathrm{mL}^{-1}$ & $36.797 \mu$ g.mL $\mathbf{m}^{-1}$ \\
\hline \multicolumn{3}{|l|}{ Temperature } \\
\hline $15^{\circ} \mathrm{C}$ & 99.6 & 99.9 \\
\hline $25^{\circ} \mathrm{C}$ & 100.7 & 100.9 \\
\hline \multicolumn{3}{|l|}{ Stability } \\
\hline $23.5 \mathrm{~h}$ & 102.4 & 100.0 \\
\hline $24.5 \mathrm{~h}$ & 102.6 & 100.5 \\
\hline \multicolumn{3}{|l|}{ Reaction time } \\
\hline $4.0 \mathrm{~min}$ & 99.8 & 99.7 \\
\hline $6.0 \mathrm{~min}$ & 102.7 & 101.2 \\
\hline
\end{tabular}




\subsection{Sensitivity (LOD and LOQ)}

The sensitivity of the method was evaluated by determining the LOD and LOQ. The values of LOD and LOQ for GLM are 0.15 and $0.46 \mu \mathrm{g} \cdot \mathrm{mL}^{-1}$, respectively.

\subsection{The homogenization of tablets}

The homogenization of tablets in terms of the weight and the amount of drug was studied. We found that the mean weight and amount drug in the tablets was $0.1793 \pm 0.0030 \mathrm{~g}$ (i.e. $\pm 1.67 \%$ ), $0.1794 \pm 0.0023 \mathrm{~g}$ (i.e. $\pm 1.17 \%$ ) for Amarium tablets ( 2 and $4 \mathrm{mg} / \mathrm{tab}$ ) and $0.1005 \pm 0.0015 \mathrm{~g}$ (i.e. $\pm 1.49 \%$ ) and $0.0993 \pm 0.0012 \mathrm{~g}$ (i.e. $\pm 1.21 \%$ ) Amapiride tablets ( 2 and $4 \mathrm{mg} / \mathrm{tab}$ ), respectively. While the mean amount drug in the tablets was $1.999 \pm 0.070 \mathrm{mg} / \mathrm{tab}$ (i.e. $\pm 3.5 \%$ ) and $3.965 \pm 0.119 \mathrm{mg} / \mathrm{tab}$ (i.e. $\pm 3.0 \%$ ) for Amarium tablets ( 2 and $4 \mathrm{mg} / \mathrm{tab}$ ) and $2.036 \pm 0.069 \mathrm{mg} / \mathrm{tab}$ (i.e. $\pm 3.4 \%$ ) and $3.945 \pm 0.122 \mathrm{mg} / \mathrm{tab}$ (i.e. $\pm 3.1 \%$ ) for Amapiride tablets $(2$ and 4 $\mathrm{mg} / \mathrm{tab})$, respectively; which shows that homogeneity of tablets is good.

\subsection{Interferences}

Metformin $\mathrm{HCL}$ up to $1000 \mathrm{mg}$ with $2 \mathrm{mg}$ of glimepiride does not interfere, but Pioglitazone $\mathrm{HCL}$ and Rosuvastatin Calcium interfere.

\section{CONCLUSION}

The developed spectrophotometric method is simple, direct (extraction-free) and cost-effective for the determination of GLM in pure and tablet dosage forms. This method is based on formation of ion-pair complex between GLM and BCP in chloroform ([GLM]: [BCP]). Beer's law in the optimum experimental conditions using [GLM]: [BCP] complex is valid within a concentration range of $1.226-46.608 \mu \mathrm{g} / \mathrm{ml}$. The developed method is applied for the determination of GLM in pure and its commercial tablets without any interference from excipients with average assay of 98.8 to $102.0 \%$.

\section{REFERENCES}

[1] O' Neil, M. J., editor 2001. The Merck Index - an Encyclopedia of Chemicals, Drugs and Biologicals. New Jersey: Merk \& Co.

[2] British pharmacopoeia. 2009. The Department of Health. Vol I. London: The Stationary office.

[3] Khedekar, P.B., Dhole, S.M., and Bhusari, K.P. 2010. Application of vierodt's and absorption correction spectrophotometric methods for estimation of rosiglitazone maleate and glimepiride in tablets. Digest J Nanomaterial and Biostructures. 5(1): 77-84.

[4] Meyer, D. 2014. Thierry. Substituent effects on absorption spectra of pH indicators: An experimental and computational study of sulfonphthaleine dyes. Dyes and Pigments. 102:241-250.

[5] Amin, A. S., Gouda, A. A., El-Sheikh, R., and Zahran, F. 2007. Spectrophotometric determination of gatifloxacin in pure form and in pharmaceutical formulation. Spectrochimica Acta Part A. 67:1306-1312.

[6] Madhusudhanareddy, I., Bhagavan, R.M., Rajendra, P.Y., and Pavankumar, R. K. 2012. Development and Validation of a Spectrophotometric Method for Quantification and Dissolution Studies of Glimepiride in Tablets. E-J Chem. 9: 993-1001.

[7] RAVINDRA. N., and SINGHVI, I. 2008. Spectrophotometric Estimation of Glimepiride from Pharmaceutical Dosage Forms. Asian Journal of Chemistry. 6: 4379-4382. 
[8] Bhargavi, S., Suryasagar, G, Sowmya, D. K., Ashok, K., and Nama, S. 2013. UV Spectrophotometric Method for Determination of Glimepiride in Pharmaceutical Dosage Forms. Int J Pharm Sci Rev Res. ;21(2): 131134.

[9] Diamont D, Lau KT, Brady S, Cleary J. 2008. Integration of analytical measurements and wireless communications-current issues and future strategies. Talanta. 75:606-612.

[10] Rahman, N., and Azmi, S.N.H. 2000. Extractive spectrophotometric methods for determination of diltiazem $\mathrm{HCl}$ in pharmaceutical formulations using bromothymol blue, bromophenol blue and bromocresol green. J Pharm Biomed Anal. 24:33-41.

[11] Rahman, N., Khan, N.A., and Azmi S.N.H. 2008. Extractive spectrophotometric methods for the determination of nifedipine in pharmaceutical formulations using bromocresol green, bromophenol blue, bromothymol blue and eriochrome black T. II Farmaco. 59: 47-54.

[12] Naveed, S., Qamar, H., Jawaid, W., and Bokhari, U. 2014. Simple UV Spectrophotometric Assay of Glimepiride. Open Sci J Clinical Medicine. 2(4): 94-101.

[13] Srivastav, A., and Maheshwari, S. 2014. Development and Validation of Multi-Component Mode UV Spectrophotometric Method for the Estimation of Metformin and Glimepiride in Combined Dosage Form. Asian J Res Chem. 7: 7-10.

[14] Priyanka, A. S., Jaivik, V. S., Mallika. S., and Pranav, S. S. 2015. Complexation Study of Glimepiride WITH $\mathrm{Mg}^{2+}, \mathrm{Ca}^{2+}, \mathrm{Cu}^{2+}$ and $\mathrm{Zn}^{2+}$ Cations in Methanol by Conductometry, Spectrophotometry and LC-MS. Int J Pharm Pharm Siec. 2015; 7(9):105-116.

[15] Altinöz, S., and Tekeli, D. 2001. Analysis of glimepiride by using derivative UV spectrophotometric method. J pharma biomedical anal. 24(3): 507-522.

[16] Sevgi, T. U. 2013. Spectrophotometric Determination of Glimepiride in Pharmaceutical Preparations Based on the Formation of Charge_Transfer and Ion_Pair Complexes. J Analyt Chem. 68(7): 606-610.

[17] Al-Tamimi, S., Alarfaj., and Al-Hashim, H. 2011. Kinetic and Spectrophotometric Methods for Determination of Two Hypoglycemic Drugs, Pioglitazone Hydrochloride and Glimepiride in their Pharmaceutical Formulations. Res J Chem Environ. 15:963-1035.

[18] Afroz, A., Tasnuva Haque, T., M. d. Mesbah Uddin Talukder, and Ashraful Islam, S.M. 2011. Spectrophotometric Estimation of Rosuvastatin Calcium and Glimepiride in Tablet Dosage Form. Asian J Pharm Ana. 1(4): 74-82.

[19] Thomas, A., Bodkhe, S., Kothapalli, L., Jangam, S., Patankar. M., Deshpande, AD. 2007. Simultaneous Spectrophotometric Estimation of Pioglitazone, Metformin $\mathrm{HCl}$ and Glimepiride in Bulk and Formulation. Asian J Chem. 19: 3821-3851.

[20] Bonfilio, R., Magali, B., de Araújob., Hérida, and R. N., Salgadoa. 2011. Development and Validation of an UV-Derivative Spectrophotometric Method for Determination of Glimepiride in Tablets. J Braz Chem Soc. 22(2): 292-301.

[21] Siddiqui, M. R., AlOthman, Z.A., and Rahman, N. 2013. Analytical techniques in pharmaceutical analysis: A review, Arabian J Chem.

[22] AL Othman, Z.A., Rahman, N., and Siddiqui, M.R. 2013. Review on pharmaceutical impurities, stability studies and degradation products: an analytical approach, Rev Adv Sci Eng. 2: 155-221. 
[23] Rahman, N., Azmi, S.N.H., and Wu H.F. 2006.The importance of impurity analysis in pharmaceutical products: an integrated approach. Accred Qual Assur. 11: 69-74.

[24] Sameer, A.M., and Basavaiah, A.K. 2012. spectrophotometric determination of dothiepin hydrochloride in pharmaceuticals through ion-pair complexation reaction. Chemical Industry \& Chemical Engineering Quarterly. 2: 339-386.

[25] Ramadan, A. A., Mandil, H., and Alsayed-Ali, R. 2015. Spectrophotometric determination of rosuvastatin in pure form and pharmaceutical formulations through ion-pair complex formation using bromocresol green. Int J Pharm Pharm Siec. 7(11):191-199.

[26] Ramadan, A. A., Mandil, H., and Zeino, S. 2016. Development and Validation of Spectrophotometric Determination of Glimepiride in Pure and Tablet Dosage Forms Through Ion-Pair Complex Formation Using Bromothymol Blue. Int J Pharm Pharm Siec. 8(6): 217-221.

[27] Ramadan, A. A., Mandil, H., and Shamseh, R. 2016. Effect of solvents on spectrophotometric determination of cefpodoxime proxetil in pure and tablet dosage form through ion-pair complex formation using bromophenol blue. Int J Pharm Pharm Siec. 8(8): 258-263.

[28] Amanlou, M., Keivani, S., Sadri, B., Gorban-Dadras, O., and Souri, E. 2009. Simple extractive colorimetric determination of buspirone by acid-dye complexation method in solid dosage form. Research in Pharmaceutical Sciences. 1: 11-19.

[29] Ashour, S., Chehna. M. F., and Bayram, R. 2006. Spectrophotometric Determination of Alfuzosin $\mathrm{HCl}$ in Pharmaceutical Formulations with some Sulphonephthalein Dyes. Int J Biomed Sci. 2(3): 273-281.

[30] Sawyer, D. T., Heineman, W. R., and Beebe, J. M. 1984. Chemistry Experiments for Instrumental Methods, Wiley, New York. 198-200.

[31] Karthik, A., Subramanian, G., Mallikarjuna Rao, C., Krishnamurthy Bhat, Ranjith Kumar, A., Musmade, P., Surulivelrajan, M., Karthikeyan, K., Udupa, N. 2008. Simultaneous determination of pioglitazone and glimepiride in bulk drug and pharmaceutical dosage form by RP-HPLC method. Pak J Pharm Sci. 21(4): 421-426.

[32] $\mathrm{ICH}$ : Proceedings of the International Conference on Harmonization of Technical Requirement of Registration of Pharmaceuticals for Human Use (ICH Harmonized Tripartite Guidelines) 2000. 